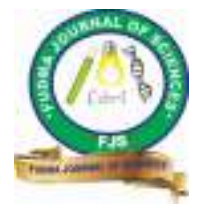

FUDMA Journal of Sciences (FJS)

ISSN online: $2616-1370$

ISSN print: 2645 - 2944

Vol. 4 No. 3, September, 2020, pp $32-35$

DOI: https://doi.org/10.33003/fjs-2020-0403-385

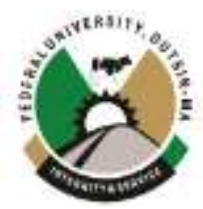

\title{
COMPARATIVE ASSESSMENT OF HEAVY METALS IN AJIWA AND JIBIA IRRIGATION DAMS OF KATSINA
} STATE, NIGERIA

\author{
${ }^{1}$ Musa, M. S., ${ }^{* 2}$ Dagari, M. S., ${ }^{3}$ Umar, A. and ${ }^{1}$ Shafiu, I. M. \\ ${ }^{1}$ Department of Pure and Industrial Chemistry, Faculty of Physical Sciences, College of Natural and Pharmaceutical Sciences, \\ Bayero University, Kano, Nigeria. \\ ${ }^{2}$ Department of Chemistry, Federal University, Gashua, Nigeria. \\ ${ }^{3}$ Department of Chemistry, Yusuf Maitama Sule University Kano, Nigeria. \\ msmusa@yahoo.com; msmusa.chm@buk.edu.ng; +2348060899099
}

\begin{abstract}
Concentrations of some heavy metals in water samples from Ajiwa and Jibia irrigation Dams of Katsina State were determined using Micro Plasma Atomic Emission Spectroscopy (MP-AES). The water samples were analyzed to determine zinc $(\mathrm{Zn})$, cadmium $(\mathrm{Cd})$, copper $(\mathrm{Cu})$, nickel $(\mathrm{Ni})$, cobalt $(\mathrm{Co})$, lead $(\mathrm{Pb})$, manganese $(\mathrm{Mn})$ and chromium $(\mathrm{Cr})$ contents. The mean concentrations $(\mathrm{mg} / \mathrm{L})$ of the heavy metals in water samples of Ajiwa and Jibia dams respectively were: zinc (1.00 $\pm 0.010,0.04 \pm 0.010)$; cadmium $(0.03 \pm 0.010$, ND); copper $(0.03 \pm 0.010, \mathrm{ND})$; lead $(0.01 \pm 0.001,0.02 \pm 0.001)$; manganese $(0.21 \pm 0.001,0.18 \pm 0.001)$; and chromium $(0.05 \pm 0.001,0.05 \pm 0.001)$, while nickel and cobalt were not detected in both samples. The P value $(0.60314)$ indicates that there is no significant difference in the metal contents between the water bodies. Assessment of these metals in both water samples shows that none of the metals was above maximum permissible limit. However, cadmium and chromium concentrations were found to be at the maximum permissible level allowed in irrigation water. These findings therefore indicated that, the two water bodies are suitable and safe for irrigation purposes.
\end{abstract}

Keywords: Ajiwa and Jibia dams, Heavy metals, Irrigation, Micro Plasma, Atomic Emission Spectroscopy.

\section{INTRODUCTION}

Water is an important resource or mineral which sustains life on earth. Therefore, its assessment to determine how safe it is in different parts of the world is very crucial. Although water quality parameters can only be defined in relative terms, however, due to increase in industrialization, population growth, and disregard for environmental health, water bodies are being used as dumping ground of contaminants or pollutants. Continual expansion of human population results in almost unimaginable amount of waste being released daily into the environment. In recent times, however, the occurrence of contaminants, especially heavy metals above natural loads, has become a problem of increasing concern (Aliyu et al., 2015).

The release of pollutants into the environment may occur naturally or due to anthropogenic activities, which ultimately results into soil, water and air pollution leading to many health hazards (Kankia and Abdulhamid, 2014). The significant alterations of industrial development in the recent past lead to increased discharge of chemical effluents into the environment, resulting in damage to aquatic life in many countries around the world. (Naeem et al., 2015). Aquatic ecosystems are especially at risk as water is an indispensable resource required for anthropogenic processes and biological functions (Beric et al., 2015)

From the chemical point of view, heavy metals are among the significant environmental pollutants that enter into the food chain (Kankia and Abdulhamid, 2014). It can also be from atmospheric deposition, geological weathering, or the discharge of waste (Esi, 2012). Knowledge of concentration of heavy metals is desirable for the estimation of meta concentration in lake water, sediment, and biota. (Muhammed and Fishar, 2005).

Due to insufficient scientific findings on Ajiwa and Jibia irrigation Dams, this study is being undertaken to assess the concentrations of heavy metals in the water bodies. It has become paramount to investigate the quality of these water bodies, as they are highly dependent on for irrigation and other vital functions they provide to the populace and residents of the state at large.

\section{MATERIALS AND METHODS \\ Reagents}

All reagents used in this study were of analytical grade purity and used without further purification. Deionized water prepared in a Milli-Di Millipore machine (SAS 67120 MOLSHEM, France) was used throughout analyses to avoid interferences by other ions. Nitric acid supplied by Thornton and Ross Huddersfield England was used for sample digestion. All plastic and glassware used were washed with detergent, rinsed with water and soaked in $10 \%(\mathrm{v} / \mathrm{v}) \mathrm{HNO}_{3}$ overnight. Finally, the items were rinsed with deionized water and dried prior to use.

\section{Sampling}

The two sampling sites are Ajiwa and Jibia. Ajiwa Dam lies on the coordinates $12^{\circ} 55^{\prime} 51^{\prime \prime} \mathrm{N} 7^{\circ} 45^{\prime} 31^{\prime \prime E}$ located at Batagarawa Local Government Area of Katsina State, while the Jibia Dam lies on the coordinates $13^{\circ} 04^{\prime} 09^{\prime \prime} \mathrm{N} 7^{\circ} 133^{\prime} 1^{\prime E}$ situated in Jibia Local Government Area of Katsina State.

The water samples were collected by dipping a two-liter polythene terephthalate container below the water surface at a depth of about one meter. The water samples were collected at 
three different points five meters away to form a composite sample. At each sampling locations, the sampling containers were rinsed three times with the water before collection. The samples were then preserved by acidifying with $2 \mathrm{~cm}^{3}$ of concentrated $\mathrm{HNO}_{3}$ in order to achieve a $\mathrm{pH}$ value of 2 and also to prevent metal adsorption onto the inner surface of the container (APHA, 2005).

\section{Sample Digestion}

The well-mixed acid preserved water sample $\left(100 \mathrm{~cm}^{3}\right)$, was transferred into a beaker $\left(250 \mathrm{~cm}^{3}\right)$. Concentrated $\mathrm{HNO}_{3}(5$ $\mathrm{cm}^{3}$ ) was then added, heated and evaporated on a hot plate until the volume reduced to about $20 \mathrm{~cm}^{3}$. Heating and addition of concentrated $\mathrm{HNO}_{3}\left(10 \mathrm{~cm}^{3}\right)$ continued until digestion was completed, as indicated by clear solution (APHA, 2005). The content was then filtered and transferred to pre-cleaned plastic bottle $\left(100 \mathrm{~cm}^{3}\right)$, cooled and diluted to mark with distilled water. A blank water sample (de-ionized water) was also digested as detailed above. Portions of these sample solutions were used for heavy metals determination using Agilent micro plasma atomic emission spectroscopy machine (MP-AES).

\section{Instrumentation}

All determinations were carried out using the Agilent Microwave Plasma Atomic Emission Spectrometer (MP-AES) equipped with an inert nebulizer and a double-pass glass cyclonic spray chamber. Liquid nitrogen was used to provide nitrogen gas to run the microwave-induced plasma. Samples were prepared by simple dilution with $1 \% \mathrm{v} / \mathrm{v} \mathrm{HNO}_{3}$ before analysis and all measurements were carried out in three (3) replicates.

\section{RESULTS AND DISCUSSION}

Table 1: Mean concentrations of heavy metals in water samples analyzed (mg/L)

\begin{tabular}{cccc}
\hline Source & $\mathrm{Zn}$ & $\mathrm{Cd}$ & $\mathrm{Cu}$ \\
\hline AW & $1.000 \pm 0.010$ & $0.030 \pm 0.010$ & $0.030 \pm 0.010$ \\
JW & $0.040 \pm 0.010$ & ND & ND
\end{tabular}

Key: $\mathrm{AW}=$ Ajiwa Water, JW=Jibia Water and $\mathrm{ND}=$ Not Detected

It can be observed from Table 1 that cadmium was not detected in sampled water from Jibia Dam, while a concentration of $0.03 \pm 0.01 \mathrm{mg} / \mathrm{L}$ was detected in sampled water from Ajiwa Dam. Ibrahim et al, (2018) reported cadmium concentration in Jibia Dam water as $0.24 \pm 0.09 \mathrm{mg} / \mathrm{L}$. This value is higher than that obtained from Ajiwa Dam $(0.030 \pm 0.010 \mathrm{mg} / \mathrm{L})$. The variation could be due to number of reasons ranging from sampling site to anthropogenic activities. Yaradua et al. (2018) reported cadmium concentration in Ajiwa water to be $0.1273 \pm$ $0.0003 \mathrm{mg} / \mathrm{L}$, which is higher than the concentration observed in this research. This could also be due to the difference in sampling time and contamination from either agricultural or domestic sources.

The maximum permissible limit of cadmium in dam water as set by WHO/FAO is $0.03 \mathrm{mg} / \mathrm{L}$, indicating that cadmium concentration in Ajiwa Dam was at the maximum allowed limit, which might cause problem to the populace using the raw water for domestic and irrigation purposes due to possible long time accumulation.

Nickel was not detected in all the water samples as reported by other researchers in Ajiwa Dam water (Yaradua et al., 2018). However, a value of $0.11 \pm 0.56 \mathrm{mg} / \mathrm{L}$ was reported by Ibrahim et al. (2018) as the concentration of nickel in Jibia water sample, this is significantly higher than the permissible concentration of $0.02 \mathrm{mg} / \mathrm{L}$ set by $\mathrm{WHO} / \mathrm{FAO}$, indicating that nickel is a threat in the water body. Furthermore, $0.208 \pm 0.02$, $0.453 \pm 0.03$ and $0.056 \pm 0.01 \mathrm{mg} / \mathrm{L}$ of nickel were recorded in Sharada industrial area irrigation water, Bompai irrigation water, and Thomas irrigation dam of Danbatta, Kano respectively. These higher values obtained could be due to the discharge of industrial effluents in the mentioned dams. Oyekunle, (2013) also reported $0.22 \mathrm{mg} / \mathrm{L}$ of Nickel in Asunle River of Obafemi Awolowo University Ile-Ife, Osun State, which is still higher than the permissible limit of $0.01 \mathrm{mg} / \mathrm{L}$. Another research conducted in Kenya by Ndede and Manohar, (2014) reported nickel concentration to be $1.11 \mathrm{mg} / \mathrm{L}$, which is higher than the values previously reported. This could be due to the numerous wastes being dumped in to the water body. In this research work, nickel is not detected in both Ajiwa and Jibia Dams and this tally with the results reported by Yaradua et al. (2018).

The concentration of lead in Ajiwa water was found to be $0.010 \pm 0.001 \mathrm{mg} / \mathrm{L}$, while that of Jibia water sample was $0.020 \pm 0.001 \mathrm{mg} / \mathrm{L}$. This value is twice the value detected in Ajiwa water sample $(0.010 \pm 0.001 \mathrm{mg} / \mathrm{L})$. These values were all below the maximum permissible limit of lead in the water $(0.05 \mathrm{mg} / \mathrm{L})$ as recommended by WHO/FAO. However, Ibrahim et al. (2018) reported the concentration of lead in Jibia water sample to be $0.096 \pm 0.03 \mathrm{mg} / \mathrm{L}$, which is significantly higher than the value obtained from the same dam in this study. This huge difference could probably be due to the difference of sampling time and contamination from either agricultural or domestic sources. In another research conducted by Malami et al. (2014), they reported the level of lead in Challawa water of Kano State to be $0.03 \pm 0.01 \mathrm{mg} / \mathrm{L}$, which is higher than the value obtained in this research, indicating that the lead concentrations in both water bodies are within the permissible liminiln anCther study c\$ibducted by Sani Hal. (2016), the leadr

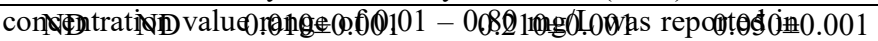

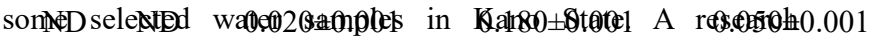
conducted by Moses (2018) showed the concentration of lead in Bagega river of Zamfara as $0.386 \pm 0.0010 \mathrm{mg} / \mathrm{L}$ which is higher than what is obtained in the present work for both Ajiwa $(0.010 \pm 0.001)$ and Jibia $(0.020 \pm 0.001)$ Dams. This higher value could be attributed to the gold mining activities taking place in the environment. From another source, $0.81 \mathrm{mg} / \mathrm{L}$ lead concentration in Ibrahim Adamu Lake of Jigawa State was reported (Sambo et al., 2014). The concentration of lead in the lake was higher than that of Jibia and Ajiwa Dams. This higher concentration could possibly be due to some contaminants close to the lake. A significantly higher value of lead $(5.94 \pm 0.740 \mathrm{mg} / \mathrm{L})$ was reported by Imam (2012) in water analyzed along Bompai-Jakara axis of Kano state. The high value could be due to the discharge of industrial effluents into the water.

Chromium concentration of $0.050 \pm 0.001 \mathrm{mg} / \mathrm{L}$ was found in both the Ajiwa and Jibia dam water bodies. A slightly lower concentration of $0.04 \pm 0.00 \mathrm{mg} / \mathrm{L}$ was reported by Malami et al. (2014) for chromium in Challawa water of Kano State, Nigeria. However, Yaradua et al. (2018) reported a value of $0.1836 \pm$ $0.0003 \mathrm{mg} / \mathrm{L}$ in Ajiwa Dam water. This variation might be due to sampling sites, anthropogenic activities and sampling times. Although $0.050 \pm 0.001 \mathrm{mg} / \mathrm{L}$ was the maximum permissible limit of chromium in dam water set by WHO/FAO, continued 
exposure of the water to this toxic metal will no doubt result to higher accumulation of the metal in the water bodies and consequently will affect the irrigation around the dams. Therefore, continuous utilization of the cultivated vegetables using these water bodies will pose danger to the final consumers. A higher value of $\mathrm{Cr}(12.3 \pm 0.84 \mathrm{mg} / \mathrm{L})$ was reported in the water basin along Bompai-Jakara axis by Imam (2012). This high value could be due to the industrial effluents in the area. A range of $0.02-0.92 \mathrm{mg} / \mathrm{L}$ of $\mathrm{Cr}$ was reported for chromium analyzed in selected water samples in Kano State (Sani et al., 2016). Another study conducted at Ibrahim Adamu Lake of Jigawa state, reported the concentration of chromium as $3.35 \mathrm{mg} / \mathrm{L}$ (Sambo et al., 2014). This value is still higher than the value obtained in the present work which, could be due to some sources of contaminations close to the lake. A concentration of $1.165 \pm 0.0040 \mathrm{mg} / \mathrm{L}$ was reported to be the concentration of chromium in Dangulbi dam of Zamfara state (Moses, 2018). This value is very high and may pose serious risk to the nearby residents.

Manganese concentrations were found to be $0.210 \pm 0.001 \mathrm{mg} / \mathrm{L}$ and $0.180 \pm 0.001 \mathrm{mg} / \mathrm{L}$ in Ajiwa and Jibia Dam water respectively. These concentrations were almost the same in both water bodies. However, in a study conducted at Challawa river water of Kano State by Uzairu et al. (2014), a value of $0.285 \pm 0.05 \mathrm{mg} / \mathrm{L}$ was reported for manganese. A value of 0.5 $\mathrm{mg} / \mathrm{L}$ is the maximum permissible limit of manganese in dam water as recommended by $\mathrm{WHO} / \mathrm{FAO}$, indicating the manganese level in all the water samples to be lower than the maximum permissible value. A range of values for manganese concentration was reported to be $0.01-3.45 \mathrm{mg} / \mathrm{L}$ in some water samples in Kano State (Sani et al., 2016). However, higher values of $0.892 \pm 0.02 \mathrm{mg} / \mathrm{L}, 0.739 \pm 0.01 \mathrm{mg} / \mathrm{L}$, and $0.112 \pm 0.001 \mathrm{mg} / \mathrm{L}$ were reported in Sharada industrial area, Bomapai industrial axis and Thomas irrigation dam water bodies respectively all from Kano State. The values were below the maximum limit recommended by WHO/FAO in water bodies. It is clear that apart from Thomas irrigation dam of Kano State with manganese concentration of $0.112 \pm 0.001$ $\mathrm{mg} / \mathrm{L}$, all the reported results were higher than the values obtained for manganese in the present work $(0.210 \pm 0.001$ and $0.180 \pm 0.001$ for Ajiwa and Jibia Dams respectively). In a similar study, $\quad 0.1271 \pm 0.0005 \mathrm{mg} / \mathrm{L}$ was reported for manganese concentration in water sample of Ajiwa Dam by Yaradua et al. (2018); the value is almost half the one obtained in this research.

Zinc concentration of $1.000 \pm 0.010 \mathrm{mg} / \mathrm{L}$ was recorded in Ajiwa water sample, being the highest of all the metal concentrations detected in all the water samples, while that of Jibia water was found to be $0.04 \pm 0.01 \mathrm{mg} / \mathrm{L}$, which is almost half the value of that of Ajiwa Dam. Another value of $0.83 \pm 0.18 \mathrm{mg} / \mathrm{L}$ was reported as zinc concentration in Challawa water of Kano State (Malami et al., 2014). However, Yaradua , (2018) reported a lower value of $0.7376 \pm 0.0004$ $\mathrm{mg} / \mathrm{L}$ for zinc in Ajiwa water sample of Katsina State. The maximum permissible limit of the essential metal set by WHO/FAO is $5.0 \mathrm{mg} / \mathrm{L}$, indicating that its concentration in all the water samples are below the maximum permissible limit. In a similar research conducted by Bala et al. (2008) on zinc concentration of Sharada industrial area irrigation water of Kano State, the concentration of the zinc was reported to be below the WHO/FAO permissible limit of $0.260 \pm 0.01 \mathrm{mg} / \mathrm{L}$. However, a higher value of $10.78 \pm 0.621 \mathrm{mg} / \mathrm{L}$ was reported in
Bompai-Jakara drainage basin water, Kano State (Imam, 2012). Cobalt was not detected in both water samples of Ajiwa and Jibia Dams. This indicates that the water samples have very low cobalt and is not a threat to the users of the water for both domestic and irrigation purposes. On the other hand, $0.354 \pm 0.015 \mathrm{mg} / \mathrm{L}$ was reported in water from Sharada industrial area of Kano, $0.191 \pm 0.01 \mathrm{mg} / \mathrm{L}$ in water samples of Bompai industrial area of Kano. These values were significantly higher than the maximum permissible limit of cobalt $(0.05 \mathrm{mg} / \mathrm{L})$ in dam water as recommended by $\mathrm{WHO} / \mathrm{FAO}$. This high value could be due to the industrial effluents released into the water bodies in these areas while cobalt was not detected completely in water sample from Thomas irrigation dam of Danbatta, Kano State (Bala et al., 2008).

A concentration of $0.030 \pm 0.010 \mathrm{mg} / \mathrm{L}$ was detected as copper concentration in Ajiwa water sample, but it was not detected completely in Jibia water sample. The maximum level of copper as recommended by WHO/FAO is $1.00 \mathrm{mg} / \mathrm{L}$, which signifies that the concentrations of copper in both water samples are below the recommended values. In a similar report by Mustapha, (2017) on Jibia water, the value of copper was found to be $0.149 \pm 0.03 \mathrm{mg} / \mathrm{L}$. This value is higher than the value obtained in this research, this can possibly be due to difference in the sampling site, anthropogenic activities or difference in period of sample collection. A value of $7.96 \pm 1.811 \mathrm{mg} / \mathrm{L}$ for copper was reported by Imam, (2012), in water samples from Bompai-Jakara industrial axis. This high value could be due to metal contamination by industrial effluents of the area. Concentration of $0.75 \mathrm{mg} / \mathrm{L}$ of copper was obtained from Ibrahim Adamu Lake of Jigawa State as reported by Sambo et al. (2014). The concentration of copper in this lake is still higher than that obtained in Jibia and Ajiwa Dams. This could be due to some sources of contaminations close to the Ibrahim Adamu lake. In a research conducted by Bala et al. (2008) on copper concentration in Bompai industrial area water samples in Kano State, the concentration was found to be $0.345 \pm 0.03 \mathrm{mg} / \mathrm{L}$. In another research conducted by Uzairu et al. (2014) on river Challawa of Kano State, they reported a lower value of $0.01 \pm 0.00 \mathrm{mg} / \mathrm{L}$ as copper concentration. Although copper was not detected in Jibia Dam water sample, copper concentration in Ajiwa Dam water $(0.030 \pm 0.010 \mathrm{mg} / \mathrm{L})$ is higher than that of Uzairu et al. (2014) but lower than that reported by Bala et al. (2008).

Generally, statistical analysis revealed a P value of 0.60314 , which is greater than 0.05 and this, indicates that there is no significant difference in the metal contents between the two water bodies (Ajiwa and Jibia Dams).

\section{CONCLUSION}

In this research, the metals (zinc, cadmium, copper, nickel, cobalt, lead, manganese and chromium) concentrations detected in water samples were observed to be within the recommended values set by international regulatory bodies (WHO/FAO). However, continuous discharge of these heavy metals from other sources, can consequently lead to levels of these metals to reach above the permissible limit as some metals are already at the maximum levels. Hence, this will result to enormous health implications not only to the aquatic species but to irrigated crops and ultimately the final consumers. The sources of these metals include agricultural runoff and urban runoff, all of which need proper monitoring to 
safeguard the health of the populace. From statistical point of view, the $\mathrm{P}$ value $(0.60314)$ which is greater than 0.05 , indicates no significant difference between the two water bodies in terms of metal accumulation.

\section{REFERENCES}

Aliyu, J. A., Saleh, Y. and Kabiru, S. (2015). Heavy metals pollution on surface water sources in Kaduna metropolis, Nigeria. Science World Journal, 10(2): 1-5.

American Public Health Association, (APHA) (2005): Standard Methods for the Examination of Water and Wastewater, 21st Edition American Public Health Association, Pp 117.

Bala, M., Shehu, R. A. and Lawal, M. (2008). Determination of the level of some heavy metals in water collected from two pollution - prone irrigation areas around kano metropolis. Bayero Journal of Pure and Applied Sciences. 1(1): 36-38

Beric, M. G., Ebrahim H., Franz, J. and Annemariè, A. O. (2015). Evaluation of Trace Element and Metal Accumulation and Edibility Risk Associated with Consumption of Labeo umbratus from the Vaal Dam, South Africa. International Journal of Environmental Research and Public Health, 2-15.

Esi, S. D. (2012). Assessment of heavy metal contamination of the Densu river, Weija from leachate. a thesis to the department of theoretical and applied biology kwame nkrumah university of science and technology. Pp 1-71

Ibrahim, M. S., Kurfi, M. Y., Sadiq, A. and Abubakar, S. (2018). Determination of level of the concentration of some heavy metals in water from Jibiya dam, Katsina state. MOJ Bioorganic \& Organic Chemistry, 243-245

Imam, T. S. (2012). Assessment of Heavy Metals Concentrations in the Surface Water of Bompai-Jakara Drainage Basin, Kano State, Northern Nigeria. Bayero Journal of Pure and Applied Sciences. 5(1): 103-108

Kankia, H. I. and Abdulhamid, Y. (2014). Determination of accumulated heavy metals in benthic invertebrates found in Ajiwa dam, Katsina state, Northern Nigeria. Archives of Applied Science Research. 6(6): 80-87.

Malami, D. I., Zakaria, Z. I., Mohammed, M. I. and Audu, A. A. (2014). Comparison of levels of some metals in the water and sediment from challawa gorge dam, Kano, Nigeria. Bayero Journal of Pure and Applied Sciences. 7(1): 80-84

Mohamed, H. H. and Fishar, M. R. A. (2005). Accumulation of trace metals in some benthic invertebrate and fish species relevant to their concentration in water and sediment of lake Qarun, Egypt. Egyptian journal of aquatic research 31(1): 1110-0354
Moses, S. (2018). Determination of Physicochemical Properties and Heavy Metal Contents in Water, Sediment and Fish in Water and Food Crops in, Zamfara State, Nigeria. A Dissertation for the award of Analytical Chemistry. Ahmadu Bello University, Zaria. Pp 1-253

Mustapha, N. (2017). Radioactivity Measurement and Heavy Metal Assessment of Soil and Water from Sugarcane Farm in Jibia. A Masters Thesis to the department of Physics. Ahmadu Bello University, Zaria.

Naeem, K., Keun, Y. R., Ji, Y. C., Eun, Y. N., Girum, H., Hoon, C., Mee, H. K., Kyung, S. P. and Kyong, S. K. (2015). Determination of toxic heavy metals and speciation of arsenic in seaweeds from South Korea. Journal of Food Chemistry. (169): 464-470

Ndede, L. A., and Manohar, S. (2014). Determination of Heavy Metals in Nairobi Dam Water, (Kenya). IOSR Journal of Environmental Science, Toxicology and Food Technology (IOSR-JESTFT). 8(5): 68-73

Oyekunle, J. A. O., Ogunfowokan, A. O., Olutona, G. O., Atoyebi, A. O. and Lawal, A. (2013). Speciation Study of Heavy Metals in Water and Sediments from Asunle River of the Obafemi Awolowo University, Ile-Ife, Nigeria. International Journal of Environmental Protection, 3(3): 6-16

Sambo, F., Haruna., I. S., Mohammed, S. and Nasir, A. (2014). Assessment of heavy metals in water and fish from Ibrahim Adamu Lake, Jigawa, Nigeria. Proceedings of 28th annual conference. Pp 179-181

Sani, A. R., Zayyad, B. and Patricia, A. E. (2016). Trace Metals Distribution in Water and Sediment from Selected Water Bodies in Kano State, Nigeria. 8th International Conference on Latest Trends in Engineering and Technology. (8): 56-60

Uzairu, A., Okunola, O. J., Wakawa, R. J. and Adewusi, S. G. (2014). Bioavailability Studies of Metals in Surface Water of River Challawa, Nigeria. Hindawi Publishing Corporation Journal of Applied Chemistry, 1-9

Yaradua, A. I., Alhassan, A. J., Nasir, A., Matazu, K. I., Muhammad, I., Idi, A., Muhammad, I.U. and Aliyu, S. M. (2018). Evaluation of Heavy Metals in Sediment of Some Selected Dams from Katsina State Nigeria. International Journal of Scientific and Technical Research in Engineering (IJSTRE), 3(2): 13-21 